\title{
Francis Bacon. La cuestión del dibujo
}

Círculo de Bellas Artes, Madrid

Del 13 de febrero al 21 de mayo de 2017

\section{La post-verdad en el dibujo de Francis Bacon}

La exposición de Francis Bacon, La cuestión del dibujo, situada en la sala Goya del Círculo de Bellas Artes de Madrid, nos hace adentrarnos en el espacio con la extraña sensación de ser nosotros, nuestra propia persona, los poseedores del don que finalmente constate la veracidad o plagio de la serie de dibujos y collages que nos disponemos escrutar. La idea de vigencia o no de la autoría de estas piezas se disipa en cuanto entramos y nos dejamos llevar por los retratos y cuerpos retorcidos, fracturados y rotos, cuya contundencia es capaz de embargar cualquier idea preconcebida.

Al acceder a la exposición entramos en la sala principal, y nos topamos con una disposición que, en un primer vistazo, podríamos encontrar monótona por su linealidad y regularidad. Sin embargo, esta regularidad dispositiva enfatiza el encuentro con el grueso de la obra de Bacon, aquella que nos hace descubrir un cuerpo traspasable.

Esta muestra, que se pudo visitar del 13 febrero al 21 de mayo de 2017, presenta 59 piezas fechadas y firmadas por el propio autor entre 1977 y 1992. Procedentes de la colección Francis Bacon Foundation of the Drawings Donated

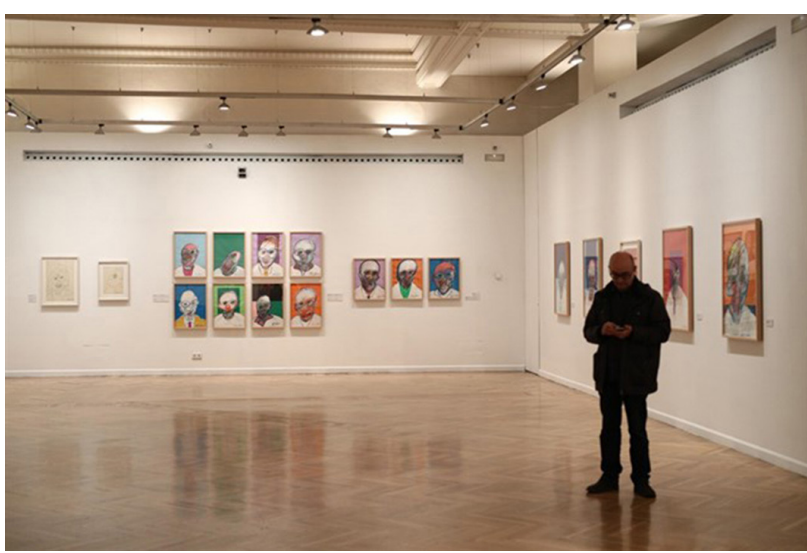

to Cristiano Lovatelli Ravarino, ha sido comisariada por el excelso crítico Fernando Castro Flórez, cuyo discurso plantea la importancia del dibujo en la obra de Francis Bacon, una apuesta que desmiente las palabras de John Richardson, quien aseguró, en el artículo publicado en el New York Review of Books en diciembre de 2009, que no es que Bacon no dibujase, sino que no sabía hacerlo.

Las obras demuestran una destreza y un dominio del espacio sobresaliente. Técnicamente la línea está ahí, pero está tan fragmentada que no delimita ninguna forma concreta, el cuerpo, los bustos o las cabezas se materializan en un espacio recortado, pero los miembros o las partes concretas son retorcidos y fragmentados. No se sabe dónde acaba uno y donde empieza otro, la colocación de sus partes no corresponde con ninguna lógica racional.

La serie de dibujos expuestos para esta ocasión muestra una aplastante coherencia con el grueso de la obra de Bacon, un desafío constante a los límites de lo representable. Como nos indica su comisario, hacen visibles las fuerzas que no lo son y que no se plasman en una figura estable, sino en un movimiento que se escapa de lo figurativo; parafraseando a Deleuze sobre Bacon, no se trata de reproducir o inventar formas, sino de captar fuerzas.

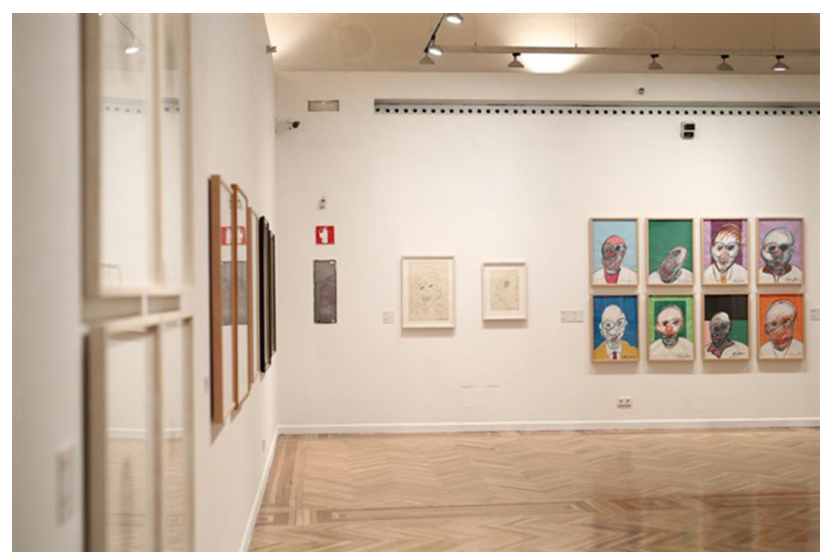


Podemos suponer que estas piezas no son bocetos ni dibujos preparatorios, sino obras por derecho propio. Técnicamente, el uso del pastel graso y grafito sobre papel puede suponer un inconveniente para mantener el fondo limpio; Francis Bacon evita esto estableciendo un espacio de color donde ubicar el cuerpo de sus propios dibujos, un collage que compone a partir de imágenes elaboradas por él mismo. Muchas de ellas de gran tamaño y apabullante colorido, en las que se repiten algunos de los temas que obsesionaron a Bacon a lo largo de su carrera, como el papa Inocencio $X$ de Velázquez, las crucifixiones o los retratos y autorretratos. Un discurso que encierra la influencia de Esquilo y Eurípides, Shakespeare, Pascal, Montaigne, Baudelaire, Nietzsche, Dostoyevski, Yeats o Ezra Pound, y que denota ese revoltijo cultural que destilan cada uno de sus temas.

Nosotros, voyeurs de este artista dañado, atendemos a un cuerpo que hurta a la presencia la apropiación del otro que nos da cuerpo, una amputación que cobra sentido en la contundencia de quien derrama y entrega ofreciendo nuevas posibilidades. Después del encuentro con Bacon o lo que sea, comprendemos esa postverdad, que los hechos objetivos pierden importancia frente a la interpelación emocional. Si es Bacon o no el autor carece de relevancia, lo importante, en este caso, es si estos dibujos alcanzan tu sistema nervioso o no, y esa es la única verdad válida que nos deja a nosotros, a cada uno de los visitantes, como últimos jueces de su autoría...; lo demás, queda eclipsado.

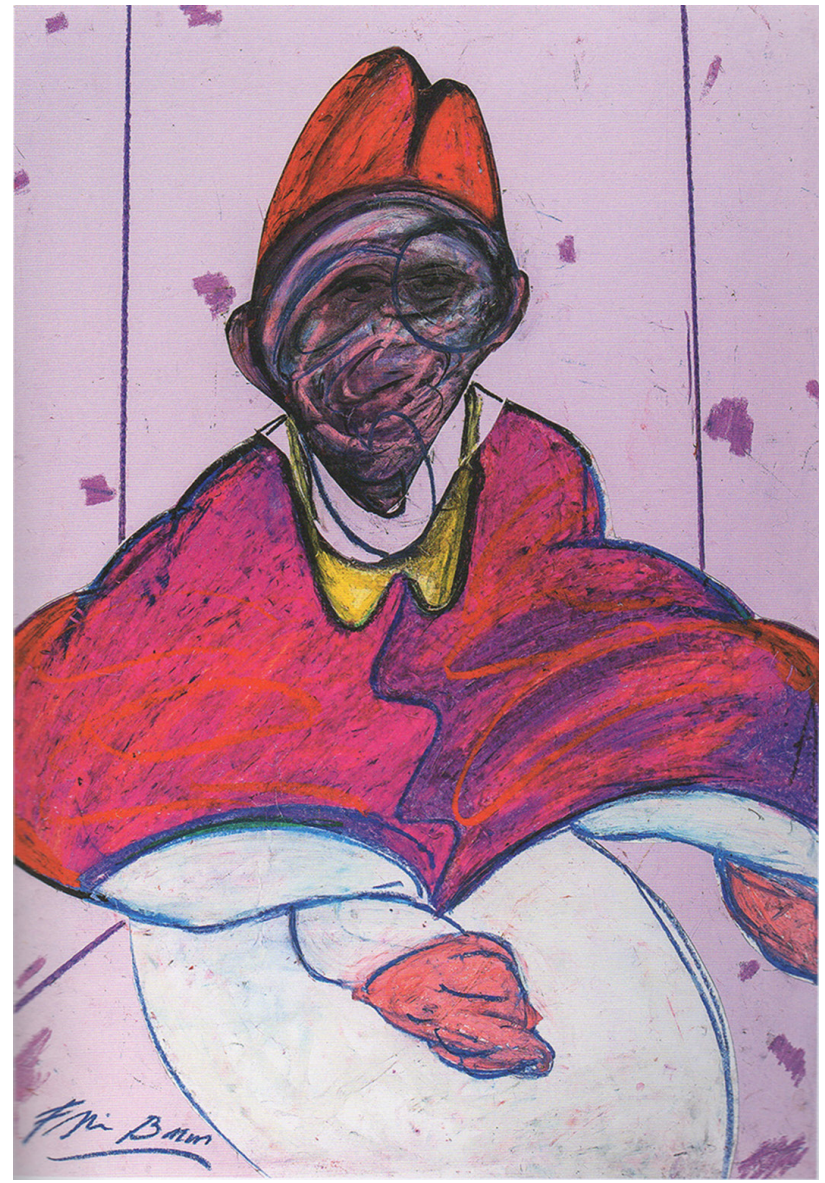

David González-Carpio Alcaraz 